J. Nonlinear Var. Anal. 6 (2022), No. 1, pp. 123-138

Available online at http://jnva.biemdas.com

https://doi.org/10.23952/jnva.6.2022.1.07

\title{
FIXED POINTS OF GENERALIZED MULTI-VALUED CONTRACTIVE MAPPINGS IN METRIC TYPE SPACES
}

\author{
ABDUL LATIF ${ }^{1, *}$, REEM FAHAD AL SUBAIE ${ }^{2}$, MONAIRAH OMAR ALANSARI ${ }^{1}$ \\ ${ }^{1}$ Department of Mathematics, King Abdulaziz University, Jeddah 21589, Saudi Arabia \\ ${ }^{2}$ Department of Mathematics, College of Science, \\ Imam Abdulrahman Bin Faisal University, Dammam 31441, Saudi Arabia
}

\begin{abstract}
In the setting of metric type spaces, we establish some new results on the existence of fixed points for generalized multi-valued contractive mappings with respect to the $w_{b}$-distance. In support of our results, some examples are also presented.
\end{abstract}

Keywords. Fixed point; Metric type space; Multi-valued contractive mapping; $w$-distance.

\section{INTRODUCTION}

The well-known Banach contraction principle [1], which asserts that "each single-valued contraction self-mapping on a complete metric space has a unique fixed point" plays a significant role in nonlinear functional analysis and optimization; see, e.g., [2, 3, 4, 5, 6] and the references therein. Recently, many fruitful generalizations of this classical fixed point result were established in various spaces. Using the Hausdorff-Pompieu metric, Nadler [7] established a multi-valued version of the Banach contraction principle, which is now one of the most useful result in metric fixed point theory. Due to this, Nadler's fixed point theorem has been generalized and investigated in various directions; see, e.g., [8, 9, 10, 11, 12] and the references therein. It is worth to mention that, for most cases, the existence part of the results can be obtained without using the Hausdorff-Pompieu metric; see, e.g., [13, 14, 15] and the references therein.

The concept of metric spaces was extended either reducing or modifying the metric axioms. One of the useful extensions is known as the metric type or $b$-metric spaces, which was introduced and studied by Bakhtin [16]. However, the authors [17, 18] initiated the study of the fixed points of self-mappings in a $b$-metric space and proved an analogue of the Banach contraction principle. Since then, various results on fixed points of single-valued and multi-valued operators have been established in $b$-metric spaces; see, e.g., [19, 20, 21] and the references therein.

In [22], Kada et al. introduced and studied the concept of the $w$-distance on a metric spaces. They improved several results by replacing the involved metric by a generalized distance. In [23], Suzuki and Takahashi introduced the notions of single-valued and multi-valued weakly

\footnotetext{
${ }^{*}$ Corresponding author.

E-mail addresses: alatif@kau.edu.sa (A. Latif),rmalsubaei@iau.edu.sa(R.F. Al Subaie), malansari@kau.edu.sa (M.O. Alansari).
}

Received July 5, 2021; Accepted September 4, 2021.

(C)2022 Journal of Nonlinear and Variational Analysis 
contractive mappings with respect to the $w$-distance and proved some fixed point results for such mappings, which improved some classical fixed point results. Further work concerning the $w$-distance can be found in [24, 25, 26]. In [27], Hussain et al. defined the $w$-distance on metric type spaces, called the $w t$-distance (here, we call it $w_{b}$-distance) and studied fixed points and common fixed points of the single-valued mappings with respect to $w_{b}$-distances. For some recent results in this direction, we refer to [27, 28, 29] and the references therein.

In this paper, we present some general fixed point results for generalized multi-valued mappings on metric type spaces with respect to $w_{b}$-distances and improve/generalize a number of known fixed point results presented in Mizoguchi-Takahashi [10], Feng-Liu [14], KlimWardowski [15], Susuki-Takahashi [23], Hussain et al. [27], Demma et al. [28], Ćirić [30], Latif-Abdou [31], Latif-Albar [32], Latif et al. [33] and several others.

\section{PRELIMINARIES}

Let $(X, d)$ be a metric space. Let $2^{X}$ denote the collection of nonempty subsets of $X, C l(X)$ denote a collection of nonempty closed subsets of $X, C B(X)$ denote a collection of nonempty closed bounded subsets of $X$, and $P(X)$ denote a collection of nonempty proximinal subsets of $X$. For any $L, M \in C B(X)$, define $H(L, M)=\max \left\{\sup _{x \in L} d(x, M), \sup _{y \in M} d(y, L)\right\}$, where $d(x, M)=\inf _{y \in M} d(x, y)$, and $H$ is known as Hausdorff-Pompieu metric on $C B(X)$.

An element $x \in X$ is called a fixed point of a multi-valued mapping $T: X \rightarrow 2^{X}$ if $x \in T(x)$. We denote the set of fixed points of $T$ by $F i x(T)=\{x \in X: x \in T(x)\}$. A sequence $\left\{x_{n}\right\}$ in $X$ is called an orbit of $\mathrm{T}$ at $x_{0} \in X$ if $x_{n} \in T\left(x_{n-1}\right)$ for all $n \geq 1$. A mapping $f: X \rightarrow \mathbb{R}$ is said to be lower semicontinuous if, for any sequence $\left\{x_{n}\right\} \subset X$ with $x_{n} \rightarrow x \in X, f(x) \leq \liminf _{n \rightarrow \infty} f\left(x_{n}\right)$.

Using the Hausdorff-Pompieu metric, Nadler [7] established the following multi-valued version of the Banach contraction principle.

Theorem 2.1. [7] Let $(X, d)$ be a complete metric space, and let $T: X \rightarrow C B(X)$ be a map such that, for a fixed constant $h \in(0,1)$ and for each $x, y \in X, H(T(x), T(y)) \leq h d(x, y)$. Then $\operatorname{Fix}(T) \neq \emptyset$.

In [10], Mizoguchi and Takahashi proved the following result, which is a real generalization [11] of the Nadler's fixed point result.

Theorem 2.2. [10] Let $(X, d)$ be a complete metric space and let $T: X \rightarrow C B(X)$. Assume that there exists a function $k:[0, \infty) \rightarrow[0,1)$ such that, for every $t \in[0, \infty), \lim \sup k(r)<1$, and, for all $x, y \in X, H(T(x), T(y)) \leq k(d(x, y)) d(x, y)$. Then Fix $(T) \neq \emptyset$.

In [14], Feng and Liu generalized Theorem 2.1 without using the Hausdorff-Pompieu metric.

Theorem 2.3. [14] Let $(X, d)$ be a complete metric space and let $T: X \rightarrow C l(X)$ be a multivalued mapping. Suppose that a real-valued function $g$ on $X, g(x)=d(x, T(x))$ is lower semicontinuous. Then Fix $(T) \neq \emptyset$ provided that there exist constants $c, h \in(0,1), h<c$ such that, for any $x \in X$, there is $y \in T(x)$ satisfying $c d(x, y) \leq g(x)$ and $g(y) \leq h d(x, y)$.

In [15], Klim and Wardowski further generalized Theorem 2.3 in the following way.

Theorem 2.4. [15] Let $(X, d)$ be a complete metric space and let $T: X \rightarrow C l(X)$ be a multivalued mapping such that a real-valued function $g$ on $X$ defined by $g(x)=d(x, T(x))$ is lower 
semi-continuous. Then Fix $(T) \neq \emptyset$ provided that there exists $c \in(0,1)$ such that, for any $x \in X$, there is $y \in T(x)$ satisfying $c d(x, y) \leq g(x)$ and $g(y) \leq k(d(x, y)) d(x, y)$, where $k$ is a function from $[0, \infty)$ to $[0, c)$ with limsup $k(r)<c$, for every $t \in[0, \infty)$.

In [30], Ćirić further unified and generalized the above mentioned theorems. In particular, the following result [30, Theorem 5] generalized Theorem 2.2.

Theorem 2.5. [30] Let $(X, d)$ be a complete metric space and let $T: X \rightarrow C l(X)$ be a multivalued mapping such that a real-valued function $g$ on $X$ defined by $g(x)=d(x, T(x))$ is lower semi-continuous. Then Fix $(T) \neq \emptyset$ provided that, for any $x \in X$, there is $y \in T(x)$ satisfying $d(x, y) \leq(2-k(d(x, y))) g(x)$ and $g(y) \leq k(d(x, y)) d(x, y)$, where $k$ is a function from $[0, \infty)$ to $[0,1)$ with $\limsup k(r)<1$, for every $t \in[0, \infty)$.

In [22], Kada et al. introduced the concept of the $w$-distance on a metric spaces as follows.

Let $(X, d)$ be a metric space. A function $p: X \times X \rightarrow[0, \infty)$ is called a $w$-distance on $X$ if it satisfies the following conditions. For each $x, y, z \in X$,

(i) $p(x, z) \leq p(x, y)+p(y, z)$;

(ii) a function $p(x, \cdot): X \rightarrow[0, \infty)$ is lower semi-continuous, i.e., if a sequence $\left\{y_{n}\right\}$ in $X$ with $y_{n} \rightarrow y \in X$, then $p(x, y) \leq \liminf _{n \rightarrow \infty} p\left(x, y_{n}\right)$;

(iii) for any $\varepsilon>0$, there exists $\delta>0$ such that $p(z, x) \leq \delta$ and $p(z, y) \leq \delta$ imply $d(x, y) \leq \varepsilon$.

Clearly, metric $d$ is a $w$-distance on $X$. Let $(Y,\|\|$.$) be a normed space. Then the functions$ $p_{1}, p_{2}: Y \times Y \rightarrow[0, \infty)$ defined by $p_{1}(x, y)=\|y\|$ and $p_{2}(x, y)=\|x\|+\|y\|$ for all $x, y \in Y$ are $w$ distances [22]. Furthermore, the examples and properties of the $w$-distance, we refer to [22, 34]. Using the concept of the $w$-distances, Kada et al. [22] improved some classical results in metric fixed point theory. In [23], Susuki and Takahashi established fixed point results for single and multi-valued contractive type mappings with respect to the $w$-distance. They improved the Banach contraction principle and Nadler's fixed point result (Theorem 2.1). On the other hand, a useful extension of a metric space is known as the metric type or $b$-metric space, which was introduced in $[17,18]$ as follows.

Let $X$ be a nonempty set, $b \geq 1$ and $D: X \times X \rightarrow[0, \infty)$ be a function satisfying the following restrictions, for all $x, y, z \in X$,

(i) $D(x, y)=0$ if and only if $x=y$;

(ii) $D(x, y)=D(y, x)$;

(iii) $D(x, y) \leq b[D(x, z)+D(z, y)]$.

Then $D$ is called a $b$-metric on $X$, and $(X, D)$ is called a $b$-metric space (also known as a metric type space [19]). In the sequel, we also call it a metric type space.

Remark 2.1. Clearly, every metric space is a metric type space. But, the converse may not be true [17]. Thus, the family of metric type spaces is effectively larger than the one of metric spaces.

Example 2.1. [16] Consider the set $X=[0,1]$ endowed with the function $D: X \times X \rightarrow[0, \infty)$, which is defined by $D(x, y)=|x-y|^{2}$, for any $x, y \in X$. Then $(X, D)$ is a metric type space with $b=2$, but it is not a metric space. 
Example 2.2. [27] Let $D: \mathbb{R} \times \mathbb{R} \rightarrow[0, \infty)$ be defined by $D(x, y)=|x-y|^{2}+\left|\frac{1}{x}-\frac{1}{y}\right|^{2}$ for any $x, y \in \mathbb{R}$. Then $(\mathbb{R}, D)$ is a metric type space with $b=2$.

Example 2.3. [35] For $0<p<1$, the space $l_{p}=\left\{\left(x_{n}\right)_{n \in \mathbb{N}} \subset \mathbb{R}\right.$, where $\left.\sum_{n=1}^{\infty} x_{n}<\infty\right\}$, which together with the mapping $D: l_{p} \times l_{p} \rightarrow \mathbb{R}$ defined by

$$
D(x, y)=\left(\sum_{n=1}^{\infty}\left|x_{n}-y_{n}\right|^{p}\right)^{1 / p}
$$

is a metric type space with $b=2^{1 / p}>1$.

For further examples of metric type spaces, we refer to [17, 20,35]. The notions of convergent sequences, Cauchy sequences, and complete spaces in the setting of metric type spaces can be defined similarly as in metric spaces; see, e.g., [19]. A subset $K$ of the metric type space $(X, D)$ is said to be open if and only if, for any $u \in K$, there exists $\varepsilon>0$ such that the open ball $B_{o}(u, \varepsilon) \subset K$. The family of all open subsets of $X$, denoted by $\tau$, defines a topology on $(X, D)$. Further, any nonempty subset $K$ of $X$ is closed if and only if, for any sequence $\left\{x_{n}\right\}$ in $K$ which converges to $x, x \in K$, for detail see [19].

Lemma 2.1. [18] Let $A$ be a closed subset of a metric type space $(X, D)$ and $x \in X$. Then $D(x, A)=0 \Leftrightarrow x \in \bar{A}=A$, where $D(x, A)=\inf \{D(x, y): y \in A\}$, and the closure of the set $A$ is denoted by $\bar{A}$.

Motivated by the work of Kada et al. [22], Hussain et al. [27] introduced the wt-distance (here we say it $w_{b}$-distance) in the setting of metric type space as follows.

Let $(X, D)$ be a metric type space with constant $b \geq 1$. Then a function $p_{b}: X \times X \rightarrow[0, \infty)$ is called a $w_{b}$-distance on $X$ if, for any $x, y, z \in X$, the following conditions are satisfied:

(i) $p_{b}(x, z) \leq b\left[p_{b}(x, y)+p_{b}(y, z)\right]$;

(ii) $p_{b}(x, \cdot): X \rightarrow[0, \infty)$ is $b$-lower semi-continuous (i.e., if, for any sequence $\left\{y_{n}\right\}$ in $X$, $y_{n} \rightarrow y \in X$, then $\left.p_{b}(x, y) \leq \liminf _{n \rightarrow \infty} b p_{b}\left(x, y_{n}\right)\right)$

(iii) for any $\varepsilon>0$, there exists $\delta>0$ such that $p_{b}(z, x) \leq \delta$ and $p_{b}(z, y) \leq \delta$ imply $D(x, y) \leq$ $\varepsilon$.

Note that, for $b=1$, each $w_{b}$-distance is a $w$-distance. Also, each $b$-metric $D$ is a $w_{b}$-distance on $X$.

Example 2.4. [27] Let $X=\mathbb{R}$ and $D(x, y)=(x-y)^{2}$. Then

(i) The function $p_{b}: X \times X \rightarrow[0, \infty)$ defined by $p_{b}(x, y)=|x|^{2}+|y|^{2}$ for every $x, y \in X$ is a $w_{b}$-distance on $X$.

(ii) The function $p_{b}: X \times X \rightarrow[0, \infty)$ defined by $p_{b}(x, y)=|y|^{2}$ for every $x, y \in X$ is a $w_{b^{-}}$ distance on $X$.

Lemma 2.2. [27] Let $(X, D)$ be a metric type space with constant $b \geq 1$, and let $p_{b}$ be $a w_{b^{-}}$ distance on $X$. Let $\left\{x_{n}\right\}$ and $\left\{y_{n}\right\}$ be sequences in $X$. Let $\left\{\alpha_{n}\right\}$ and $\left\{\beta_{n}\right\}$ be sequences in $[0, \infty)$ converging to zero, and let $x, y, z \in X$. Then the following assertions hold:

(i) if $p_{b}\left(x_{n}, y\right) \leq \alpha_{n}$ and $p_{b}\left(x_{n}, z\right) \leq \beta_{n}$ for any $n \in \mathbb{N}$, then $y=z$. In particular, if $p_{b}(x, y)=0$ and $p_{b}(x, z)=0$, then $y=z$;

(ii) if $p_{b}\left(x_{n}, y_{n}\right) \leq \alpha_{n}$ and $p_{b}\left(x_{n}, z\right) \leq \beta_{n}$ for any $n \in \mathbb{N}$, then $D\left(y_{n}, z\right) \rightarrow 0$; 
(iii) if $p_{b}\left(x_{n}, x_{m}\right) \leq \alpha_{n}$ for any $n, m \in \mathbb{N}$ with $m>n$, then $\left\{x_{n}\right\}$ is a Cauchy sequence;

(iv) if $p_{b}\left(y, x_{n}\right) \leq \alpha_{n}$ for any $n \in \mathbb{N}$, then $\left\{x_{n}\right\}$ is a Cauchy sequence.

Lemma 2.3. [33] Let $A$ be a closed subset of a metric type space $(X, D)$, and let $p_{b}$ be a $w_{b^{-}}$ distance on $X$. Suppose that there exists $u \in X$ such that $p_{b}(u, u)=0$. Then $p_{b}(u, A)=0 \Leftrightarrow u \in$ $A$, where $p_{b}(u, A)=\inf \left\{p_{b}(u, v): v \in A\right\}$.

The objective of this paper is to present some more general results on the existence of fixed points for multi-valued mappings with respect to the $w_{b}$-distance. We unify and generalize a number of known fixed point results in the metric fixed point theory, including the corresponding fixed results presented in this section.

\section{Main Results}

First, we prove a fixed point result, which is a generalization of Ćirić [30, Theorem 5], in the setting of metric type spaces.

Theorem 3.1. Let $(X, D)$ be a complete metric type space with a $w_{b}$-distance $p_{b}$. Let $T: X \rightarrow$ $\mathrm{Cl}(X)$ be a multi-valued mapping such that a real-valued function $g$ on $X$ defined by $g(x)=$ $p_{b}(x, T(x))$ is b-lower semi-continuous. Assume that the following conditions hold:

(i) there is a function $\varphi$ from $[0,+\infty)$ to $[0,1)$ with $\limsup _{r \rightarrow t^{+}} \varphi(r)<1$, for every $t \in$ $[0,+\infty)$;

(ii) for any $x \in X$, there is $y \in T(x)$ satisfying

$$
p_{b}(x, y) \leq\left(2-\varphi\left(p_{b}(x, y)\right)\right) g(x)
$$

and

$$
g(y) \leq \varphi\left(p_{b}(x, y)\right) p_{b}(x, y) .
$$

Then, there exists $u_{0} \in X$ such that $g\left(u_{0}\right)=0$. Further, if $p_{b}\left(u_{0}, u_{0}\right)=0$, then $u_{0} \in T\left(u_{0}\right)$.

Proof. Let $x_{0} \in X$ be an arbitrary but fixed element of $X$. From (ii), we see that there exists $x_{1} \in T\left(x_{0}\right)$ such that

$$
p_{b}\left(x_{0}, x_{1}\right) \leq\left(2-\varphi\left(p_{b}\left(x_{0}, x_{1}\right)\right)\right) p_{b}\left(x_{0}, T\left(x_{0}\right)\right)
$$

and

$$
p_{b}\left(x_{1}, T\left(x_{1}\right)\right) \leq \varphi\left(p_{b}\left(x_{0}, x_{1}\right)\right) p_{b}\left(x_{0}, x_{1}\right) .
$$

Thus,

$$
p_{b}\left(x_{1}, T\left(x_{1}\right)\right) \leq \varphi\left(p_{b}\left(x_{0}, x_{1}\right)\right)\left(2-\varphi\left(p_{b}\left(x_{0}, x_{1}\right)\right)\right) p_{b}\left(x_{0}, T\left(x_{0}\right)\right) .
$$

Define a function $\psi:[0,+\infty) \rightarrow[0,+\infty)$ by

$$
\psi(t)=\varphi(t)(2-\varphi(t))=1-(1-\varphi(t))^{2} .
$$

Since, for each $t \in[0,+\infty), \varphi(t)<1$, and $\limsup _{r \rightarrow t^{+}} \varphi(r)<1$, we obtain $\psi(t)<1$ and

$$
\limsup _{r \rightarrow t^{+}} \psi(r)<1, \quad \text { for all } t \in[0,+\infty) \text {. }
$$

From (3.1) and (3.2), we have

$$
p_{b}\left(x_{1}, T\left(x_{1}\right)\right) \leq \psi\left(p_{b}\left(x_{0}, x_{1}\right)\right) p_{b}\left(x_{0}, T\left(x_{0}\right)\right) .
$$


Similarly, for $x_{1} \in X$, there exists $x_{2} \in T\left(x_{1}\right)$ such that

$$
p_{b}\left(x_{1}, x_{2}\right) \leq\left(2-\varphi\left(p_{b}\left(x_{1}, x_{2}\right)\right)\right) p_{b}\left(x_{1}, T\left(x_{1}\right)\right)
$$

and

$$
p_{b}\left(x_{2}, T\left(x_{2}\right)\right) \leq \psi\left(p_{b}\left(x_{1}, x_{2}\right)\right) p_{b}\left(x_{1}, T\left(x_{1}\right)\right) .
$$

Continuing this process, we obtain an orbit $\left\{x_{n}\right\}$ of $T$ at $x_{0} \in X$ such that $x_{n+1} \in T\left(x_{n}\right)$ satisfies

$$
p_{b}\left(x_{n}, x_{n+1}\right) \leq\left(2-\varphi\left(p_{b}\left(x_{n}, x_{n+1}\right)\right)\right) p_{b}\left(x_{n}, T\left(x_{n}\right)\right)
$$

and

$$
p_{b}\left(x_{n+1}, T\left(x_{n+1}\right)\right) \leq \psi\left(p_{b}\left(x_{n}, x_{n+1}\right)\right) p_{b}\left(x_{n}, T\left(x_{n}\right)\right)
$$

for each $n \geq 0$. Since $\psi(t)<1$ for each $t \in[0,+\infty)$, we have, for all $n \geq 0$

$$
p_{b}\left(x_{n+1}, T\left(x_{n+1}\right)\right)<p_{b}\left(x_{n}, T\left(x_{n}\right)\right) \text {. }
$$

Thus, the sequence of non-negative real numbers $\left\{p_{b}\left(x_{n}, T\left(x_{n}\right)\right)\right\}$ is strictly decreasing and bounded below, thus convergent. Therefore, there is some $\alpha \geq 0$ such that

$$
\lim _{n \rightarrow \infty} p_{b}\left(x_{n}, T\left(x_{n}\right)\right)=\alpha .
$$

Note that, for each $n, p_{b}\left(x_{n}, T\left(x_{n}\right)\right) \leq p_{b}\left(x_{n}, x_{n+1}\right)$, and since $\varphi(t)<1$ for each $t \in[0,+\infty)$, we conclude from (3.4) that, for each $n$,

$$
p_{b}\left(x_{n}, x_{n+1}\right)<2 p_{b}\left(x_{n}, T\left(x_{n}\right)\right) .
$$

Thus, the sequence $\left\{p_{b}\left(x_{n}, x_{n+1}\right)\right\}$ is bounded. Therefore, there is some $\beta \geq 0$ such that

$$
\liminf _{n \rightarrow \infty} p_{b}\left(x_{n}, x_{n+1}\right)=\beta \text {. }
$$

Note that $\alpha \leq \beta$. First, we show that $\alpha=\beta$. Suppose that $\alpha=0$. Then, $\lim _{n \rightarrow \infty} p_{b}\left(x_{n}, x_{n+1}\right)=$ 0 , and thus $\beta=0$. Now, for $\alpha>0$, we suppose that $\alpha \neq \beta$. Then $\beta-\alpha>0$, and it follows from (3.6) and (3.8) that there is a positive integer $n_{0}$ such that

$$
p_{b}\left(x_{n}, T\left(x_{n}\right)\right)<\alpha+\frac{\beta-\alpha}{4}, \quad \forall n \geq n_{0},
$$

and

$$
\beta-\frac{\beta-\alpha}{4}<p_{b}\left(x_{n}, x_{n+1}\right), \quad \forall n \geq n_{0} .
$$

Using (3.4), (3.9) and (3.10), we have

$$
\begin{aligned}
\beta-\frac{\beta-\alpha}{4} & <p_{b}\left(x_{n}, x_{n+1}\right) \\
& \leq\left(2-\varphi\left(p_{b}\left(x_{n}, x_{n+1}\right)\right)\right) p_{b}\left(x_{n}, T\left(x_{n}\right)\right) \\
& <\left(2-\varphi\left(p_{b}\left(x_{n}, x_{n+1}\right)\right)\right)\left[\alpha+\frac{\beta-\alpha}{4}\right] .
\end{aligned}
$$

Thus, for all $n \geq n_{0}$, we have

$$
\left(2-\varphi\left(p_{b}\left(x_{n}, x_{n+1}\right)\right)\right)>\frac{3 \beta+\alpha}{3 \alpha+\beta},
$$

that is,

$$
1+\left(1-\varphi\left(p_{b}\left(x_{n}, x_{n+1}\right)\right)\right)>1+\frac{2(\beta-\alpha)}{3 \alpha+\beta}
$$


It follows that

$$
-\left(1-\varphi\left(p_{b}\left(x_{n}, x_{n+1}\right)\right)\right)^{2}<-\left[\frac{2(\beta-\alpha)}{3 \alpha+\beta}\right]^{2} .
$$

Thus, for all $n \geq n_{0}$, we have

$$
\begin{aligned}
\psi\left(p_{b}\left(x_{n}, x_{n+1}\right)\right) & =1-\left(1-\varphi\left(p_{b}\left(x_{n}, x_{n+1}\right)\right)\right)^{2} \\
& <1-\left[\frac{2(\beta-\alpha)}{3 \alpha+\beta}\right]^{2} .
\end{aligned}
$$

Take $\lambda=1-\left[\frac{2(\beta-\alpha)}{3 \alpha+\beta}\right]^{2}$. From (3.5) and (3.11), one has

$$
p_{b}\left(x_{n+1}, T\left(x_{n+1}\right)\right)<\lambda p_{b}\left(x_{n}, T\left(x_{n}\right)\right), \quad \forall n \geq n_{0} .
$$

Since $\beta>\alpha$, one has $\lambda<1$. From (3.12), one has, for any $l \geq 1$,

$$
p_{b}\left(x_{n_{0}+l}, T\left(x_{n_{0}+l}\right)\right)<\lambda^{l} p_{b}\left(x_{n_{0}}, T\left(x_{n_{0}}\right)\right) .
$$

As $\alpha>0$ and $\lambda<1$, there is a positive integer $l_{0}$ such that $\lambda^{l_{0}} p_{b}\left(x_{n_{0}}, T\left(x_{n_{0}}\right)\right)<\alpha$. Note that $\alpha \leq p_{b}\left(x_{n}, T\left(x_{n}\right)\right)$ for each $n \geq 0$. Thus, it follows from (3.13) that

$$
\alpha \leq p_{b}\left(x_{n_{0}+l_{0}}, T\left(x_{n_{0}+l_{0}}\right)\right)<\lambda^{l_{0}} p_{b}\left(x_{n_{0}}, T\left(x_{n_{0}}\right)\right)<\alpha,
$$

which is a contradiction. Hence $\alpha=\beta$. Now we show that $\alpha=0$. Suppose $\alpha>0$. Since

$$
\beta=\alpha \leq p_{b}\left(x_{n}, T\left(x_{n}\right)\right) \leq p_{b}\left(x_{n}, x_{n+1}\right),
$$

then from (3.8) we can find $\liminf _{n \rightarrow \infty} p_{b}\left(x_{n}, x_{n+1}\right)=\beta^{+}$, where $\beta^{+}$means $\beta>0$. So, there exists a subsequence $\left\{p_{b}\left(x_{n_{l}}, x_{n_{l}+1}\right)\right\}$ of $\left\{p_{b}\left(x_{n}, x_{n+1}\right)\right\}$ such that $\lim _{l \rightarrow \infty} p_{b}\left(x_{n_{l}}, x_{n_{l}+1}\right)=\beta^{+}$. Now from (3.3) we have

$$
\limsup _{p_{b}\left(x_{n_{l}}, x_{n_{l}+1}\right) \rightarrow \beta^{+}} \psi\left(p_{b}\left(x_{n_{l}}, x_{n_{l}+1}\right)\right)<1
$$

and from (3.5), we have

$$
p_{b}\left(x_{n_{l}+1}, T\left(x_{n_{l}+1}\right)\right) \leq \psi\left(p_{b}\left(x_{n_{l}}, x_{n_{l}+1}\right)\right) p_{b}\left(x_{n_{l}}, T\left(x_{n_{l}}\right)\right) .
$$

Letting $l \rightarrow \infty$ and using (3.6), we arrive at

$$
\begin{aligned}
\alpha & =\limsup _{l \rightarrow \infty} p_{b}\left(x_{n_{l}+1}, T\left(x_{n_{l}+1}\right)\right) \\
& \leq\left(\limsup _{l \rightarrow \infty}\left(\psi\left(p_{b}\left(x_{n_{l}}, x_{n_{l}+1}\right)\right)\right)\right)\left(\limsup _{l \rightarrow \infty}\left(p_{b}\left(x_{n_{l}}, T\left(x_{n_{l}}\right)\right)\right)\right) \\
& =\left(\limsup _{p_{b}\left(x_{n_{l}}, x_{n_{l}+1}\right) \rightarrow \beta+} \psi\left(p_{b}\left(x_{n_{l}}, x_{n_{l}+1}\right)\right)\right) \alpha .
\end{aligned}
$$

Since $\alpha>0$, then it follows from the last inequality that

$$
1 \leq \limsup _{p_{b}\left(x_{n_{l}}, x_{n_{l}+1}\right) \rightarrow \beta^{+}} \psi\left(p_{b}\left(x_{n_{l}}, x_{n_{l}+1}\right)\right),
$$

which contradicts (3.14). Hence, $\alpha=0$. In view of (3.6) and (3.7), we obtain

$$
\lim _{n \rightarrow \infty} p_{b}\left(x_{n}, T\left(x_{n}\right)\right)=0
$$

and thus $\lim _{n \rightarrow \infty} p_{b}\left(x_{n}, x_{n+1}\right)=0$. 
Next, we show that $\left\{x_{n}\right\}$ is a Cauchy sequence. Let

$$
\delta=\limsup _{p_{b}\left(x_{n_{l}}, x_{n_{l}+1}\right) \rightarrow 0} \psi\left(p_{b}\left(x_{n_{l}}, x_{n_{l}+1}\right)\right) .
$$

From (3.3), one has $\delta<1$. We choose $k \in\left(0, b^{-1}\right)$ such that $\delta<k<1$. Then there exists some $n_{0} \in \mathbb{N}$ such that $\psi\left(p_{b}\left(x_{n}, x_{n+1}\right)\right)<k, \forall n \geq n_{0}$. From (3.5), we have

$$
p_{b}\left(x_{n+1}, T\left(x_{n+1}\right)\right) \leq k p_{b}\left(x_{n}, T\left(x_{n}\right)\right), \quad \forall n \geq n_{0} .
$$

By induction, we obtain

$$
p_{b}\left(x_{n+1}, T\left(x_{n+1}\right)\right) \leq k^{n+1-n_{0}} p_{b}\left(x_{n_{0}}, T\left(x_{n_{0}}\right)\right), \quad \forall n \geq n_{0} .
$$

A combination of (3.7) and (3.16) yields

$$
p_{b}\left(x_{n}, x_{n+1}\right) \leq 2 k^{n-n_{0}} p_{b}\left(x_{n_{0}}, T\left(x_{n_{0}}\right)\right), \quad \forall n \geq n_{0} .
$$

Since $p_{b}$ is the $w_{b}$-distance, for any $n, m \in \mathbb{N}, m>n$, we have

$$
\begin{aligned}
p_{b}\left(x_{n}, x_{m}\right) \leq & b\left[p_{b}\left(x_{n}, x_{n+1}\right)+p_{b}\left(x_{n+1}, x_{m}\right)\right] \\
\leq & b p_{b}\left(x_{n}, x_{n+1}\right)+b\left(b\left[p_{b}\left(x_{n+1}, x_{n+2}\right)+p_{b}\left(x_{n+2}, x_{m}\right)\right]\right) \\
= & b p_{b}\left(x_{n}, x_{n+1}\right)+b^{2} p_{b}\left(x_{n+1}, x_{n+2}\right)+b^{2} p_{b}\left(x_{n+2}, x_{m}\right) \\
\leq & b p_{b}\left(x_{n}, x_{n+1}\right)+b^{2} p_{b}\left(x_{n+1}, x_{n+2}\right) \\
& +b^{2}\left(b\left[p_{b}\left(x_{n+2}, x_{n+3}\right)+p_{b}\left(x_{n+3}, x_{m}\right)\right]\right) \\
= & b p_{b}\left(x_{n}, x_{n+1}\right)+b^{2} p_{b}\left(x_{n+1}, x_{n+2}\right) \\
& +b^{3}\left(p_{b}\left(x_{n+2}, x_{n+3}\right)+p_{b}\left(x_{n+3}, x_{m}\right)\right) \\
\vdots \quad & \\
\leq & b p_{b}\left(x_{n}, x_{n+1}\right)+b^{2} p_{b}\left(x_{n+1}, x_{n+2}\right)+\ldots \\
& +b^{m-n-1}\left(p_{b}\left(x_{m-2}, x_{m-1}\right)+p_{b}\left(x_{m-1}, x_{m}\right)\right) .
\end{aligned}
$$

Using (3.17) and (3.18) we obtain

$$
\begin{aligned}
p_{b}\left(x_{n}, x_{m}\right) \leq & 2 b k^{n-n_{0}} p_{b}\left(x_{n_{0}}, T\left(x_{n_{0}}\right)\right)+2 b^{2} k^{n-n_{0}+1} p_{b}\left(x_{n_{0}}, T\left(x_{n_{0}}\right)\right)+\ldots \\
& +2 b^{m-n-1} k^{m-n_{0}-2} p_{b}\left(x_{n_{0}}, T\left(x_{n_{0}}\right)\right)+2 b^{m-n-1} k^{m-n_{0}-1} p_{b}\left(x_{n_{0}}, T\left(x_{n_{0}}\right)\right) \\
= & 2 b k^{n-n_{0}}\left(1+b k+(b k)^{2}+\ldots+(b k)^{m-n-2}+b^{m-n-2} k^{m-n-1}\right) p_{b}\left(x_{n_{0}}, T\left(x_{n_{0}}\right)\right) .
\end{aligned}
$$

As $b k<1$, we obtain, for all $m, n \in \mathbb{N}$ with $m>n \geq n_{0}$,

$$
p_{b}\left(x_{n}, x_{m}\right) \leq \frac{2 b k^{n-n_{0}}}{1-b k} p_{b}\left(x_{n_{0}}, T\left(x_{n_{0}}\right)\right) \text {. }
$$

Since $\frac{2 b k^{n-n_{0}}}{1-b k} \rightarrow 0$ as $n \rightarrow+\infty$, we conclude from Lemma 2.2 (iii) that $\left\{x_{n}\right\}$ is a Cauchy sequence in $X$. Due to the completeness of $X$, there exists some $u_{0} \in X$ such that $\left\{x_{n}\right\}$ converges to $u_{0}$. Now, by using the $b$-lower semi-continuity of function $g$ and (3.15), we obtain

$$
0 \leq g\left(u_{0}\right) \leq \liminf _{n \rightarrow \infty} b g\left(x_{n}\right)=0,
$$

and hence, $g\left(u_{0}\right)=p_{b}\left(u_{0}, T\left(u_{0}\right)\right)=0$. If $p_{b}\left(u_{0}, u_{0}\right)=0$, then it follows from Lemma 2.3 that $u_{0} \in T\left(u_{0}\right)$ as $T\left(u_{0}\right)$ is closed. 
Remark 3.1. (i) Theorem 3.1 generalizes Theorem 2.5 ([30, Theorem 5]) and the fixed point results [10, Theorem 5]. Indeed, if $b=1$ and $p_{b}=d$ in Theorem 3.1, then we obtain Theorem 2.5 immediately.

(ii) Theorem 3.1 includes the fixed point result [31, Theorem 2.1] as a special case when $b=1$.

Replacing the $b$-lower semi-continuity of the real-valued function $g$ of Theorem 3.1 with another suitable condition, we obtain the following fixed point result, which generalizes [31, Theorem 2.2].

Theorem 3.2. Suppose that all the hypotheses of Theorem 3.1 hold except the b-lower semicontinuity of $g$. Assume that $\inf \left\{p_{b}(x, u)+p_{b}(x, T(x)): x \in X\right\}>0$, for every $u \in X$ with $u \notin$ $T(u)$. Then Fix $(T) \neq \emptyset$.

Proof. Following the proof of Theorem 3.1, there exists an orbit $\left\{x_{n}\right\}$ of $T$, which is a Cauchy sequence in $X$. Due to the completeness of $X$, there exists $u_{0} \in X$ such that $\left\{x_{n}\right\}$ converges to $u_{0}$. Since $p_{b}\left(x_{n}, \cdot\right)$ is $b$-lower semi-continuous and $\lim _{m \rightarrow \infty} x_{m}=u_{0} \in X$, it follows from the proof of Theorem 3.1 that, for all $n \geq n_{0}$,

$$
p_{b}\left(x_{n}, u_{0}\right) \leq \liminf _{m \rightarrow \infty} b p_{b}\left(x_{n}, x_{m}\right) \leq \frac{2 b^{2} k^{n-n_{0}}}{1-b k} p_{b}\left(x_{n_{0}}, T\left(x_{n_{0}}\right)\right) .
$$

On the other hand, we have

$$
p_{b}\left(x_{n}, T\left(x_{n}\right)\right) \leq p_{b}\left(x_{n}, x_{n+1}\right) \leq 2 k^{n-n_{0}} p_{b}\left(x_{n_{0}}, T\left(x_{n_{0}}\right)\right) .
$$

Letting $u_{0} \notin T\left(u_{0}\right)$, we have

$$
\begin{aligned}
0 & <\inf \left\{p_{b}\left(x, u_{0}\right)+p_{b}(x, T(x)): x \in X\right\} \\
& \leq \inf \left\{p_{b}\left(x_{n}, u_{0}\right)+p_{b}\left(x_{n}, T\left(x_{n}\right)\right): n \geq n_{0}\right\} \\
& \leq \inf \left\{\frac{2 b^{2} k^{n-n_{o}}}{1-b k} p_{b}\left(x_{n_{0}}, T\left(x_{n_{0}}\right)\right)+2 k^{n-n_{0}} p_{b}\left(x_{n_{0}}, T\left(x_{n_{0}}\right)\right): n \geq n_{0}\right\} \\
& =\frac{2 k^{-n_{0}}\left(b^{2}-b k+1\right)}{1-b k} p_{b}\left(x_{n_{0}}, T\left(x_{n_{0}}\right)\right) \inf \left\{k^{n}: n \geq n_{0}\right\}=0,
\end{aligned}
$$

which is impossible. Hence, $u_{0} \in \operatorname{Fix}(T)$.

Now, we present a general result on the existence of fixed points for multi-valued mappings, which improve/generalize a number of known fixed point results.

Theorem 3.3. Let $(X, D)$ be a complete metric type space with a $w_{b}$-distance $p_{b}$. Let $T$ : $X \rightarrow C l(X)$ be a multi-valued mapping such that the real-valued function $g$ on $X$ defined by $g(x)=p_{b}(x, T(x))$ is b-lower semi-continuous. Assume that the following conditions hold:

(i) there are functions $\varphi:[0,+\infty) \rightarrow(0,1)$ and $\mu:[0,+\infty) \rightarrow[c, 1)$, with $c>0$. Here $\mu$ is nondecreasing such that $\varphi(t)<\mu(t)$ and $\limsup _{r \rightarrow t^{+}} \varphi(r)<\limsup _{r \rightarrow t^{+}} \mu(r)$, for every $t \in[0,+\infty)$;

(ii) for any $x \in X$, there exists $y \in T(x)$ satisfying

$$
\mu\left(p_{b}(x, y)\right) p_{b}(x, y) \leq g(x)
$$

and

$$
g(y) \leq \varphi\left(p_{b}(x, y)\right) p_{b}(x, y)
$$


Then there exists $u_{0} \in X$ such that $g\left(u_{0}\right)=0$. Further, if $p_{b}\left(u_{0}, u_{0}\right)=0$, then $u_{0} \in T\left(u_{0}\right)$.

Proof. Let $x_{0} \in X$ be an arbitrary but fixed element of $X$. Then there exists $x_{1} \in T\left(x_{0}\right)$ such that

$$
\mu\left(p_{b}\left(x_{0}, x_{1}\right)\right) p_{b}\left(x_{0}, x_{1}\right) \leq p_{b}\left(x_{0}, T\left(x_{0}\right)\right)
$$

and

$$
p_{b}\left(x_{1}, T\left(x_{1}\right)\right) \leq \varphi\left(p_{b}\left(x_{0}, x_{1}\right)\right) p_{b}\left(x_{0}, x_{1}\right) .
$$

It follows that

$$
p_{b}\left(x_{1}, T\left(x_{1}\right)\right) \leq \frac{\varphi\left(p_{b}\left(x_{0}, x_{1}\right)\right)}{\mu\left(p_{b}\left(x_{0}, x_{1}\right)\right)} p_{b}\left(x_{0}, T\left(x_{0}\right)\right) .
$$

Define a function $\psi:[0,+\infty) \rightarrow[0,+\infty)$ by

$$
\psi(t)=\frac{\varphi(t)}{\mu(t)}, \quad \forall t \in[0,+\infty) .
$$

Since, for each $t \in[0,+\infty), \varphi(t)<\mu(t)$, we have $\psi(t)<1$ and

$$
\limsup _{r \rightarrow t^{+}} \psi(r)<1, \quad \forall t \in[0,+\infty) .
$$

From (3.19), we have

$$
p_{b}\left(x_{1}, T\left(x_{1}\right)\right) \leq \psi\left(p_{b}\left(x_{0}, x_{1}\right)\right) p_{b}\left(x_{0}, T\left(x_{0}\right)\right) .
$$

Similarly, for $x_{1} \in X$, there exists $x_{2} \in T\left(x_{1}\right)$ such that

$$
\mu\left(p_{b}\left(x_{1}, x_{2}\right)\right) p_{b}\left(x_{1}, x_{2}\right) \leq p_{b}\left(x_{1}, T\left(x_{1}\right)\right)
$$

and

$$
p_{b}\left(x_{2}, T\left(x_{2}\right)\right) \leq \varphi\left(p_{b}\left(x_{1}, x_{2}\right)\right) p_{b}\left(x_{1}, x_{2}\right) .
$$

Thus

$$
p_{b}\left(x_{2}, T\left(x_{2}\right)\right) \leq \psi\left(p_{b}\left(x_{1}, x_{2}\right)\right) p_{b}\left(x_{1}, T\left(x_{1}\right)\right) .
$$

Continuing this process, we can obtain an orbit $\left\{x_{n}\right\}$ of $T$ in $X$ satisfying

$$
\mu\left(p_{b}\left(x_{n}, x_{n+1}\right)\right) p_{b}\left(x_{n}, x_{n+1}\right) \leq p_{b}\left(x_{n}, T\left(x_{n}\right)\right),
$$

and

$$
p_{b}\left(x_{n+1}, T\left(x_{n+1}\right)\right) \leq \varphi\left(p_{b}\left(x_{n}, x_{n+1}\right)\right) p_{b}\left(x_{n}, x_{n+1}\right) .
$$

Hence, we have

$$
p_{b}\left(x_{n+1}, T\left(x_{n+1}\right)\right) \leq \psi\left(p_{b}\left(x_{n}, x_{n+1}\right)\right) p_{b}\left(x_{n}, T\left(x_{n}\right)\right),
$$

for all $n \geq 0$. Since $\psi(t)<1$ for each $t \in[0,+\infty)$, we have, for all $n \geq 0$

$$
p_{b}\left(x_{n+1}, T\left(x_{n+1}\right)\right)<p_{b}\left(x_{n}, T\left(x_{n}\right)\right) .
$$

Thus, $\left\{p_{b}\left(x_{n}, T\left(x_{n}\right)\right)\right\}$ is strictly decreasing and bounded below, thus it is convergent. Therefore, there is some $\alpha \geq 0$ such that $\lim _{n \rightarrow \infty} p_{b}\left(x_{n}, T\left(x_{n}\right)\right)=\alpha$. Now, we need to show that $\left\{p_{b}\left(x_{n}, x_{n+1}\right)\right\}$ is also strictly decreasing. Assume that $p_{b}\left(x_{n}, x_{n+1}\right) \leq p_{b}\left(x_{n+1}, x_{n+2}\right)$. Since $\mu(t)$ is nondecreasing, we have

$$
\mu\left(p_{b}\left(x_{n}, x_{n+1}\right)\right) \leq \mu\left(p_{b}\left(x_{n+1}, x_{n+2}\right)\right) .
$$


Using (3.21), (3.22) and (3.24) with $n=n+1$, we arrive at

$$
\begin{aligned}
p_{b}\left(x_{n+1}, x_{n+2}\right) & \leq \frac{\varphi\left(p_{b}\left(x_{n}, x_{n+1}\right)\right)}{\mu\left(p_{b}\left(x_{n+1}, x_{n+2}\right)\right)} p_{b}\left(x_{n}, x_{n+1}\right) \\
& \leq \frac{\varphi\left(p_{b}\left(x_{n}, x_{n+1}\right)\right)}{\mu\left(p_{b}\left(x_{n}, x_{n+1}\right)\right)} p_{b}\left(x_{n}, x_{n+1}\right) \\
& =\psi\left(p_{b}\left(x_{n}, x_{n+1}\right)\right) p_{b}\left(x_{n}, x_{n+1}\right) \\
& <p_{b}\left(x_{n}, x_{n+1}\right),
\end{aligned}
$$

which is a contradiction. Hence, $\left\{p_{b}\left(x_{n}, x_{n+1}\right)\right\}$ is strictly decreasing. Therefore, there exists some $\beta \geq 0$ such that $\lim _{n \rightarrow \infty} p_{b}\left(x_{n}, x_{n+1}\right)=\beta^{+}$. In view of (3.23), we obtain

$$
\begin{aligned}
\alpha & \leq\left(\limsup _{n \rightarrow \infty} \psi\left(p_{b}\left(x_{n}, x_{n+1}\right)\right)\right) \alpha \\
& =\left(\limsup _{p_{b}\left(x_{n}, x_{n+1}\right) \rightarrow \beta^{+}} \psi\left(p_{b}\left(x_{n}, x_{n+1}\right)\right)\right) \alpha .
\end{aligned}
$$

By using (3.20), we conclude that $\alpha=0$. In view of $\mu \geq c$, we conclude from (3.21) that

$$
p_{b}\left(x_{n}, x_{n+1}\right) \leq \frac{1}{c} p_{b}\left(x_{n}, T\left(x_{n}\right)\right), \quad \forall n \geq n_{0}
$$

Since $\left\{p_{b}\left(x_{n}, T\left(x_{n}\right)\right)\right\} \rightarrow 0$, we have $\left\{p_{b}\left(x_{n}, x_{n+1}\right)\right\} \rightarrow 0$. Now, we let

$$
\delta=\limsup _{n \rightarrow \infty} \psi\left(p_{b}\left(x_{n}, x_{n+1}\right)\right)
$$

From (3.20), we have $\delta<1$. Choose $k \in\left(0, b^{-1}\right)$ such that $\delta<k<1$. Then there exists some $n_{0} \in \mathbb{N}$ such that

$$
\psi\left(p_{b}\left(x_{n}, x_{n+1}\right)\right)<k, \quad \forall n \geq n_{0}
$$

It follows from (3.23),

$$
p_{b}\left(x_{n+1}, T\left(x_{n+1}\right)\right) \leq k p_{b}\left(x_{n}, T\left(x_{n}\right)\right), \quad \forall n \geq n_{0} .
$$

By induction, we have

$$
p_{b}\left(x_{n+1}, T\left(x_{n+1}\right)\right) \leq k^{n+1-n_{0}} p_{b}\left(x_{n_{0}}, T\left(x_{n_{0}}\right)\right), \quad \forall n \geq n_{0} .
$$

Using (3.25) and (3.26), we have

$$
p_{b}\left(x_{n}, x_{n+1}\right) \leq \frac{1}{c} p_{b}\left(x_{n}, T\left(x_{n}\right)\right) \leq \frac{1}{c} k^{n-n_{0}} p_{b}\left(x_{n_{0}}, T\left(x_{n_{0}}\right)\right), \quad \forall n \geq n_{0}
$$


Next, we show that $\left\{x_{n}\right\}$ is a Cauchy sequence. From (3.27), for all $m>n \geq n_{0}$, we have

$$
\begin{aligned}
p_{b}\left(x_{n}, x_{m}\right) \leq & b\left[p_{b}\left(x_{n}, x_{n+1}\right)+p_{b}\left(x_{n+1}, x_{m}\right)\right] \\
\leq & b p_{b}\left(x_{n}, x_{n+1}\right)+b\left(b\left[p_{b}\left(x_{n+1}, x_{n+2}\right)+p_{b}\left(x_{n+2}, x_{m}\right)\right]\right) \\
= & b p_{b}\left(x_{n}, x_{n+1}\right)+b^{2} p_{b}\left(x_{n+1}, x_{n+2}\right)+b^{2} p_{b}\left(x_{n+2}, x_{m}\right) \\
\leq & b p_{b}\left(x_{n}, x_{n+1}\right)+b^{2} p_{b}\left(x_{n+1}, x_{n+2}\right)+b^{2}\left(b\left[p_{b}\left(x_{n+2}, x_{n+3}\right)+p_{b}\left(x_{n+3}, x_{m}\right)\right]\right) \\
= & b p_{b}\left(x_{n}, x_{n+1}\right)+b^{2} p_{b}\left(x_{n+1}, x_{n+2}\right)+b^{3}\left(p_{b}\left(x_{n+2}, x_{n+3}\right)+p_{b}\left(x_{n+3}, x_{m}\right)\right) \\
\vdots & \\
\leq & b p_{b}\left(x_{n}, x_{n+1}\right)+b^{2} p_{b}\left(x_{n+1}, x_{n+2}\right)+\ldots \\
& +b^{m-n-1}\left(p_{b}\left(x_{m-2}, x_{m-1}\right)+p_{b}\left(x_{m-1}, x_{m}\right)\right) \\
\leq & \frac{1}{c} b k^{n-n_{0}} p_{b}\left(x_{n_{0}}, T\left(x_{n_{0}}\right)\right)+\frac{1}{c} b^{2} k^{n-n_{0}+1} p_{b}\left(x_{n_{0}}, T\left(x_{n_{0}}\right)\right)+\ldots \\
& +\frac{1}{c} b^{m-n-1} k^{m-n_{0}-2} p_{b}\left(x_{n_{0}}, T\left(x_{n_{0}}\right)\right)+\frac{1}{c} b^{m-n-1} k^{m-n_{0}-1} p_{b}\left(x_{n_{0}}, T\left(x_{n_{0}}\right)\right) \\
= & \frac{1}{c} b k^{n-n_{0}}\left(1+b k+(b k)^{2}+\ldots+(b k)^{m-n-2}+b^{m-n-2} k^{m-n-1}\right) p_{b}\left(x_{n_{0}}, T\left(x_{n_{0}}\right)\right) \\
\leq & \frac{1}{c} b k^{n-n_{0}}\left(1+b k+(b k)^{2}+\ldots\right) p_{b}\left(x_{n_{0}}, T\left(x_{n_{0}}\right)\right) .
\end{aligned}
$$

Since $b k<1$, for $m, n \in \mathbb{N}$ with $m>n \geq n_{0}$, we obtain

$$
p_{b}\left(x_{n}, x_{m}\right) \leq \frac{1}{c}\left(\frac{b k^{n-n_{0}}}{1-b k}\right) p_{b}\left(x_{n_{0}}, T\left(x_{n_{0}}\right)\right) \text {. }
$$

Since $\frac{1}{c}\left(\frac{b k^{n-n_{0}}}{1-b k}\right) \rightarrow 0$ as $n \rightarrow+\infty$, we conclude from Lemma 2.2 (iii) that $\left\{x_{n}\right\}$ is a Cauchy sequence. Thanks to the completeness of $X$, there exists some $u_{0} \in X$ such that $\left\{x_{n}\right\}$ converges to $u_{0}$. Since $g$ is $b$-lower semi-continuous, we have

$$
0 \leq g\left(u_{0}\right) \leq \liminf _{n \rightarrow \infty} b g\left(x_{n}\right)=0,
$$

and thus, $g\left(u_{0}\right)=p_{b}\left(u_{0}, T\left(u_{0}\right)\right)=0$. Now, if $p_{b}\left(u_{0}, u_{0}\right)=0$, then it follows from Lemma 2.3 that $u_{0} \in T\left(u_{0}\right)$ as $T\left(u_{0}\right)$ is closed.

Remark 3.2. (i) If we consider $b=1$ and the $w_{b}$-distance function $p_{b}$ equals to the distance $d$ in Theorem 3.3, then it reduces to [30, Theorem 6] and thus it also generalizes Theorem 2.2, [10, Theorem 5].

(ii) Theorem 3.3 includes Theorem 2.4, [15, Theorem 2.1], as a special case. Indeed, if we consider a constant mapping $\mu(t)=a$ in Theorem 3.3, for all $t \in[0, \infty)$ and $a \in(0,1)$, $b=1$, and the $w_{b}$-distance function $p_{b}=d$, then we obtain [15, Theorem 2.1].

(iii) If we take $b=1$ in Theorem 3.3, then we have a fixed point result [31, Theorem 2.3].

The conclusion of Theorem 3.3 is still valid if we replace the $b$-lower semi-continuity of realvalued function $g$ with another suitable assumption. Consequently, the following result includes [31, Theorem 2.4] as a special case.

Theorem 3.4. Suppose that all the hypotheses of Theorem 3.3 hold except the b-lower semicontinuity of the function $g$. Assume that $\inf \left\{p_{b}(x, u)+p_{b}(x, T(x)): x \in X\right\}>0$, for every $u \in X$ with $u \notin T(u)$. Then Fix $(T) \neq \emptyset$. 
Finally, we present a fixed point result, which is a generalization of the results [15, Theorem 2.2], [30, Theorem 7], and [31, Theorem 2.5].

Theorem 3.5. Let $(X, D)$ be a complete metric type space with a $w_{b}$-distance $p_{b}$. Let $T: X \rightarrow$ $P(X)$ be a multi-valued mapping such that a real-valued function $g$ on $X$ defined by $g(x)=$ $p_{b}(x, T(x))$ is b-lower semi-continuous. Assume that the following conditions hold:

(i) there is a function $\varphi:[0,+\infty) \rightarrow[0,1)$ such that, for each $t \in[0,+\infty), \limsup _{r \rightarrow t^{+}} \varphi(r)<$ 1 ;

(ii) for any $x \in X$, there is $y \in T(x)$ satisfying $p_{b}(x, y)=g(x)$ and $g(y) \leq \varphi\left(p_{b}(x, y)\right) p_{b}(x, y)$. Then there exists $u_{0} \in X$ such that $g\left(u_{0}\right)=0$. Further, if $p_{b}\left(u_{0}, u_{0}\right)=0$, then $u_{0} \in T\left(u_{0}\right)$.

Proof. Let $x_{0} \in X$ be an arbitrary but fixed element of $X$. From (ii), we can choose $x_{1} \in T\left(x_{0}\right)$ such that $p_{b}\left(x_{0}, x_{1}\right)=p_{b}\left(x_{0}, T\left(x_{0}\right)\right), p_{b}\left(x_{1}, T\left(x_{1}\right)\right) \leq \varphi\left(p_{b}\left(x_{0}, x_{1}\right)\right) p_{b}\left(x_{0}, x_{1}\right)$, and $\varphi\left(p_{b}\left(x_{0}, x_{1}\right)\right)$ $<1$. Continuing this process, we obtain a sequence $\left\{x_{n}\right\}$ such that $x_{n+1} \in T\left(x_{n}\right)$ and $p_{b}\left(x_{n}, x_{n+1}\right)$ $=p_{b}\left(x_{n}, T\left(x_{n}\right)\right), p_{b}\left(x_{n+1}, T\left(x_{n+1}\right)\right) \leq \varphi\left(p_{b}\left(x_{n}, x_{n+1}\right)\right) p_{b}\left(x_{n}, x_{n+1}\right)$, and $\varphi\left(p_{b}\left(x_{n}, x_{n+1}\right)\right)<1$. Following the method in the proof of Lemma 2.1 [33], one can easily show that $\left\{x_{n}\right\}$ is a Cauchy sequence in $X$. Thanks to the completeness of $X$, there exists $u_{0} \in X$ such that $\left\{x_{n}\right\}$ converges to $u_{0}$. Since $g$ is $b$-lower semi-continuous, we have $0 \leq g\left(u_{0}\right) \leq \liminf _{n \rightarrow \infty} b g\left(x_{n}\right)=0$, and thus, $g\left(u_{0}\right)=p_{b}\left(u_{0}, T\left(u_{0}\right)\right)=0$. Since $p_{b}\left(u_{0}, u_{0}\right)=0$, and $T\left(u_{0}\right)$ is closed, it follows from Lemma 2.3 that $u_{0} \in T\left(u_{0}\right)$.

Remark 3.3. (i) Theorem 3.5 generalizes the fixed point result due to Ćirić[30, Theorem 7] and thus also generalizes [15, Theorem 2.2]. Indeed, if $b=1$ and $p_{b}=d$ in Theorem 3.5, then it reduces to [30, Theorem 7].

(ii) If $b=1$ in Theorem 3.5, then we obtain [31, Theorem 2.5].

\section{EXAMPLES}

The following example shows that Theorem 3.1 is a real generalization of Ćirić [30, Theorem 5] and Latif and Abdou [31, Theorem 2.1].

Example 4.1. Let $X=[0,1]$. Define $D(x, y)=(x-y)^{2}$ for all $x, y \in X$. Then $X$ is a metric type space with $b=2$. Define a $w_{b}$-distance function on $X$ by $p_{b}(x, y)=y^{2}$, for all $x, y \in X$. Let $T: X \rightarrow C l(X)$ be defined by

$$
T(x)= \begin{cases}\left\{\frac{1}{2} x^{2}\right\}, & x \in\left[0, \frac{15}{32}\right) \cup\left(\frac{15}{32}, 1\right], \\ \left\{\frac{17}{96}, \frac{1}{4}\right\}, & x=\frac{15}{32},\end{cases}
$$

and define a function $\varphi:[0, \infty) \rightarrow[0,1)$ by

$$
\varphi(t)= \begin{cases}\frac{3}{4} t, & t \in\left[0, \frac{1}{2}\right), \\ \frac{3}{8}, & t \in\left[\frac{1}{2}, \infty\right) .\end{cases}
$$

Then,

$$
g(x)=p_{b}(x, T(x))= \begin{cases}\frac{1}{4} x^{4}, & x \in\left[0, \frac{15}{32}\right) \cup\left(\frac{15}{32}, 1\right] \\ \left(\frac{17}{96}\right)^{2}, & x=\frac{15}{32}\end{cases}
$$


and $g$ is $b$-lower semi-continuous. For each $x \in\left[0, \frac{15}{32}\right) \cup\left(\frac{15}{32}, 1\right]$, there exists $y \in T(x)=\left\{\frac{1}{2} x^{2}\right\}$ such that $p_{b}(x, y)=p_{b}(x, T(x))=\frac{1}{4} x^{4}$. Thus, for each $x \in[0,1], x \neq \frac{15}{32}$, we have

$$
p_{b}(x, y)=\frac{1}{4} x^{4} \leq\left(2-\varphi\left(p_{b}(x, y)\right)\right) \frac{1}{4} x^{4}=\left(2-\varphi\left(p_{b}(x, y)\right)\right) p_{b}(x, T(x))
$$

and

$$
\begin{aligned}
p_{b}(y, T(y)) & =p_{b}\left(\frac{1}{2} x^{2}, \frac{1}{2}\left(\frac{1}{2} x^{2}\right)^{2}\right)=\left(\frac{1}{8} x^{4}\right)^{2}=\frac{1}{16} x^{4} p_{b}(x, y) \\
& \leq \frac{3}{16} x^{4} p_{b}(x, y)=\varphi\left(p_{b}(x, y)\right) p_{b}(x, y) .
\end{aligned}
$$

Letting $x=\frac{15}{32}$, we have $T(x)=\left\{\frac{17}{96}, \frac{1}{4}\right\}$. Clearly, there exists $y=\frac{17}{96} \in T(x)$ such that

$$
p_{b}(x, y)=\left(\frac{17}{96}\right)^{2} \leq\left(2-\frac{3}{4}\left(\frac{17}{96}\right)^{2}\right)\left(\frac{17}{96}\right)^{2}=\left(2-\varphi\left(p_{b}(x, y)\right)\right) p_{b}(x, T(x))
$$

and

$$
\begin{aligned}
p_{b}(y, T(y)) & =p_{b}\left(\frac{17}{96}, \frac{1}{2}\left(\frac{17}{96}\right)^{2}\right)=\frac{1}{4}\left(\frac{17}{96}\right)^{4} \\
& =\frac{1}{4}\left(\frac{17}{96}\right)^{2} p_{b}(x, y) \\
& \leq \frac{3}{4}\left(\frac{17}{96}\right)^{2} p_{b}(x, y)=\varphi\left(p_{b}(x, y)\right) p_{b}(x, y) .
\end{aligned}
$$

Thus, for each $x \in[0,1]$, all the conditions of Theorem 3.1 are satisfied. Hence, it follows that $\operatorname{Fix}(T) \neq \emptyset$. Note that $\operatorname{Fix}(T)=\{0\}$. Clearly, the $w_{b}$-distance $p_{b}$ is not a metric $d$, so $T$ does not satisfy the hypotheses of Theorem 2.5 [30, Theorem 5]. In addition, the $w_{b}$-distance $p_{b}$ is not a $w$-distance $p$, so $T$ does not satisfy the hypotheses of [31, Theorem 2.1].

Finally, we present an example, which shows that Theorem 3.5 is a real generalization of Klim-Wardowski [15, Theorem 2.2], Ćirić [30, Theorem 7], and Latif and Abdou [31, Theorem 2.5].

Example 4.2. For $b=2$, consider the metric type space $X=[0, \infty)$ with $D(x, y)=(x-y)^{2}$ for all $x, y \in X$. Define a $w_{b}$-distance function on $X$ by $p_{b}(x, y)=x^{2}+y^{2}$, for all $x, y \in X$. Now, for any real number $a>1$, define $T: X \rightarrow C l(X)$ by

$$
T(x)=\left\{\frac{x}{a}\right\} \cup[(1+2 x), \infty), \quad \forall x \in[0, \infty),
$$

and define a constant function $\varphi:[0, \infty) \rightarrow[0,1)$ by $\varphi(t)=\frac{1}{a^{2}}$, for all $t \in[0, \infty)$. Note that $\varphi(t)<1$ for all $t \in[0, \infty)$. For each $x \in X$, we have

$$
g(x)=p_{b}(x, T(x))=x^{2}+\left(\frac{x}{a}\right)^{2}=\left(\frac{a^{2}+1}{a^{2}}\right) x^{2} .
$$

Further, for each $x \in X$, there exists $y=\frac{x}{a} \in T(x)$ such that

$$
p_{b}(x, y)=p_{b}\left(x, \frac{x}{a}\right)=p_{b}(x, T(x)),
$$


and

$$
p_{b}(y, T(y))=p_{b}\left(\frac{x}{a}, \frac{x}{a^{2}}\right)=\frac{x^{2}}{a^{2}}+\frac{x^{2}}{a^{4}}=\frac{1}{a^{2}}\left(\frac{a^{2}+1}{a^{2}}\right) x^{2}=\varphi\left(p_{b}(x, y)\right) p_{b}(x, y) .
$$

Therefore, all the assumptions of Theorem 3.5 are satisfied. We conclude $F i x(T)=\{0\}$. Note that $T(x)$ is not a compact for all $x \in X$, and the $w_{b}$-distance $p_{b}$ is not a metric $d$ (even not a $w$-distance $p$ on $X$ ). Consequently [15, Theorem 2.2], [30, Theorem 7], and [31, Theorem 2.5] are not applicable.

\section{REFERENCES}

[1] S. Banach, Sur les opérations dans les ensembles abstraits et leur applications aux équations intégrales, Fund. Math. 3 (1922), 133-181.

[2] P. Cubiotti, J.C. Yao, On the Cauchy problem for a class of differential inclusions with applications, Appl. Anal. 99 (2020), 2543-2554.

[3] J. Fan, A subgradient extragradient algorithm with inertial effects for solving strongly pseudomonotone variational inequalities, Optimization, 69 (2020), 2199-2215.

[4] A. Latif, Banach contraction principal and its generalizations, In: S. Almezel, Q.H. Ansari, and M.A. Khamsi (ed.), Topics in fixed point theory, pp. 33-64, Springer, Cham, 2014.

[5] L. Liu, S.Y. Cho, J.C. Yao, Convergence analysis of an inertial Tseng's extragradient algorithm for solving pseudomonotone variational inequalities and applications, J. Nonlinear Var. Anal. 5 (2021), 627-644.

[6] J. Fan, X. Qin, B. Tan, Tseng's extragradient algorithm for pseudomonotone variational inequalities on Hadamard manifolds, Appl. Anal. 10.1080/00036811.2020.1807012.

[7] S.B. Nadler, Multi-valued contraction mappings, Pacific J. Math. 30 (1969), 475-488.

[8] S.K. Malhotra, S. Prakash, S. Shukla, A generalization of Nadler theorem in cone b-metric spaces over Banach algebras, Commun. Optim. Theory, 2019 (2019), Article ID 10.

[9] O. Popescu, G. Stan, A generalization of Nadler's fixed point theorem, Results in Math. 72 (2017), 15251534.

[10] N. Mizoguchi, W. Takahashi, Fixed point theorems for multivalued mappings on complete metric spaces, J. Math. Anal. Appl. 141 (1989), 177-188.

[11] T. Suzuki, Mizoguchi-Takahashi's fixed point theorem is a real generalization of Nadler's, J. Math. Anal. Appl. 340 (2008), 752-755.

[12] E.U. Ofoedu, K.O. Ibeh, C.B. Osigwe, L.O. Madu, C.G. Ezea, The existence and approximation for solutions of variational inclusion problems, Appl. Set-Valued Anal. Optim. 3 (2021), 221-237.

[13] L.B. Ćirić, Multivalued nonlinear contraction mappings, Nonlinear Anal. 71 (2009), 2716-2723.

[14] Y. Feng, S. Liu, Fixed point theorems for multi-valued contractive mappings and multi-valued Caristi type mappings, J. Math. Anal. Appl. 317 (2006), 103-112.

[15] D. Klim, D. Wardowski, Fixed point theorems for set-valued contractions in complete metric spaces, J. Math. Anal. Appl. 334 (2007), 132-139.

[16] I.A. Bakhtin, The contraction mapping principle in almost metric spaces, Funct. Anal. Gos. Ped. Inst. Unianowsk, 30 (1989), 26-37.

[17] S. Czerwik, Nonlinear set-valued contraction mappings in $b$-metric spaces, Atti Semin. Mat. Fis. Univ. Modena, 46 (1998), 263-276.

[18] S. Czerwick, K. Dlutek, S. L. Singh, Round-off stability of iteration procedures for set-valued operators in $b$-metric spaces, J. Nat. Phys. Sci. 11 (2001), 87-94.

[19] M.A. Khamsi, N. Hussain, KKM mappings in metric type spaces, Nonlinear Anal. 73 (2010), 3123-3129.

[20] G. Petrusel, T. Lazar, V.L. Lazar, Fixed points and coupled fixed points for multi-valued $(\varphi, \psi)$-contractions in $b$-metric spaces, Appl. Anal. Optim. 18 (2016), 99-112.

[21] P. Hu, F. Gu, Some fixed point theorems of $\lambda$-contractive mappings in Menger PSM-spaces, J. Nonlinear Funct. Anal. 2020 (2020), Article ID 33.

[22] O. Kada, T. Suzuki, W. Takahashi, Nonconvex minimization theorems and fixed point theorems in complete metric spaces, Math. Japonicae, 44 (1996), 381-391. 
[23] T. Suzuki, W. Takahashi, Fixed point theorems and characterizations of metric completeness, Topol. Meth. Nonlinear Anal. 8 (1996), 371-382.

[24] A. Latif, B. Bin Dehaish, A. Al Rwaily, Metric fixed point results for generalized contractive mapping and applications, J. Nonlinear Convex Anal. 19 (2018), 2177-2188.

[25] A. Latif, L. Guran, M-F. Bota, Ulam-Hyers stability problems and fixed points for contractive type operators on KST-spaces, Linear Nonlinear Anal. 5 (2019), 379-390.

[26] Z. Liu, X. Wang, S.M. Kang, S. Y. Cho, Fixed points for mappings satisfying some multi-valued contractions with $w$-distance, Fixed Point Theory Appl. 2014 (2014), 1-17.

[27] N. Hussain, R. Saadati, R.P. Agrawal, On the topology and wt-distance on metric type spaces, Fixed Point Theory Appl. 2014 (2014), 1-14.

[28] M. Demma, R. Saadati, P. Vetro, Multi-valued operators with respect $w t$-distance on metric type spaces, Bull. Iranian Math. Soc. 42 (2016), 1571-1582.

[29] K. Fallahi, D. Savic, G. Soleimani Rad, The existence theorem for contractive mappings on wt-distance in $b$-metric spaces endowed with a graph and its application, Sahand Commun. Math. Anal. 13 (2019), 1-15.

[30] L.B. Ćirić, Fixed point theorems for multi-valued contractions in complete metric spaces, J. Math. Anal. App. 348 (2008), 499-507.

[31] A. Latif, A.A.N. Abdou, Fixed points results for generalized contractive multimaps in metric spaces, Fixed Point Theory Appl. 2009 (2009), Article ID 432130.

[32] A. Latif, W.A. Albar, Fixed point results in complete metric spaces, Demonstratio Math. 41 (2008), 145-150.

[33] A. Latif, R.F. Al Subaie, M.O. Alansari, Metric fixed points for contractive type mappings and applications, in press.

[34] W. Takahashi, Nonlinear Functional Analysis: Fixed Point Theory and Its Applications, Yokohama, 2000.

[35] V. Berinde, Generalized contractions in quasimetric spaces, Seminar on Fixed Point Theory, 3 (1993), 3-9. 